\title{
ina \\ A Demand Response Implementation with Building Energy Management System
}

\author{
Prasertsak Charoen (1), Nathavuth Kitbutrawat (1) and Jasada Kudtongngam * (1)
}

check for updates

Citation: Charoen, P.; Kitbutrawat,

N.; Kudtongngam, J. A Demand

Response Implementation with

Building Energy Management

System. Energies 2022, 15, 1220

https://doi.org/10.3390/en15031220

Academic Editor: Maria del Mar

Castilla Nieto

Received: 20 December 2021

Accepted: 19 January 2022

Published: 8 February 2022

Publisher's Note: MDPI stays neutral with regard to jurisdictional claims in published maps and institutional affiliations.

Copyright: (C) 2022 by the authors. Licensee MDPI, Basel, Switzerland. This article is an open access article distributed under the terms and conditions of the Creative Commons Attribution (CC BY) license (https:// creativecommons.org/licenses/by/ $4.0 /)$.

\author{
National Electronics and Computer Technology Center, National Science and Technology Development Agency, \\ 112 Phahonyothin Road, Khlong Nueng, Khlong Luang District, Pathum Thani 12120, Thailand; \\ prasertsak.cha@ncr.nstda.or.th (P.C.); nathavuth.kitbutrawat@nectec.or.th (N.K.) \\ * Correspondence: jasada.kudtongngam@nectec.or.th
}

\begin{abstract}
The demand response (DR) program is one of the most promising components in the development of the Smart Grid. However, there are many challenges in practical operation to improve the existing and outdated system to comply with the DR programs. In Thailand, the major pain point of the office building owner in the DR program is the additional equipment, modification and operation cost of the existing equipment. Moreover, the sophisticated solution and control are other obstacles that need more measurements and data, and they make the operation difficult to work with. In this paper, we implemented a simple yet cost-effective hardware and software solution targeting an outdated air-conditioning system without voiding the warranty of the outdated equipment and without installing any additional measurements. In addition, the proposed operation is designed to be easy to operate under the equipment limitation and unskilled labor. More importantly, indoor temperature setpoint schedules during the DR event are forecasted with some public datasets to determine the capacity of the energy management system that can reduce the power consumption in the office building without an effect on the occupants' comfort. To confirm the practicality of the proposed solution, the actual operation of the proposed solution can achieve the maximum power reduction at $19.80 \mathrm{~kW}\left(43.79 \%\right.$ of the maximum power consumption) while keeping only $1{ }^{\circ} \mathrm{C}$ of difference from the typical room temperature $\left(26-28^{\circ} \mathrm{C}\right)$.
\end{abstract}

Keywords: building energy management system; demand response; interruptible load program; OpenADR; temperature setpoint

\section{Introduction}

The demand response (DR) program is a set of time-dependent activities from electric grid operators that provide control strategies when the electric grid is near its capacity, especially during peak demand hours [1-5]. There are many countries that aim to deploy the DR policy to cope with the avoided cost of new power plant investment. Moreover, the DR program is one of the procedures for climate change mitigation because it can decrease the load of electric energy usage. Currently, electricity is mostly generated from fossil fuels that contribute to carbon dioxide emissions and increase the rate of global warming. Commercial and office buildings produce a large portion of the world's carbon dioxide emissions and energy consumption [6,7].

The DR programs also play a role in the forced and unpredicted outage events. To maintain the utility grid during the emergency events, consumers are requested to respond to a load reduction request. According to the annual report of the Electricity Generating Authority of Thailand (EGAT) in 2020 [8], forced outages occurred 53 times, with the total electricity supply cut off for $7960.98 \mathrm{MW}-$ Minutes. One of the outage events that had an impact on the power system happened at 5:35 on 14 February 2020. In addition, the power shortage is also one of the major power system stability measures. To cope with the increasing demand in the electricity power and the power shortage when the power 
plants have the annual overhaul schedule, consumers are also requested to reduce the load consumption. Then, the utility company and the electricity generating company require a quick response to reduce the power consumption in both the unpredicted outage and the power shortage events.

To cope with both the unpredicted outage and power shortages events in Thailand, the resolution of the National Energy Policy Committee (NEPC) was approved in 2011. In order to comply with the resolution, the Energy Regulatory Commission (ERC) has been assigned to conduct a study on the development of measure and scheme solutions for Thailand. The ERC had approved a new electricity tariff structure in 2015, which promotes the reduction of electricity usage. The appropriate DR measures for Thailand can be summarized, such as the Emergency Demand Response Program (EDRP), Critical Peak Pricing (CPP) and the Interruptible Load Program (ILP). The EDRP is designed to reduce electricity consumption during peak periods or crisis events, and the DR event will be sent in a short period, e.g., one day or one hour ahead. In addition, the CPP will help the participants or customers to plan and manage their electricity usage. In both the EDRP and CPP, there is no penalty for the participants or customers who join the programs. Even though the ILP will motivate the participants with the incentive or special tariff rate, there is a penalty that will be agreed upon in advance. The ERC will promote and encourage the industrial and commercial users who can join this ILP program to achieve the resolution of the NEPC.

Both the EDRP and ILP will help us to deal with both emergency and power shortage events; however, there are the investment and maintenance costs to make the existing system comply with the DR programs. Comparing the incentive or special tariff, the additional cost of improving the existing system is very high. However, many works have been studied in the literature in recent years related to building DR programs without concerning in the additional cost and the practical operation. Even though most of the DR strategies for buildings focus on peak load reduction and energy saving while maintaining occupant comfort, these related works also require more measurements and the controllable parameter of the simulation. Many DR strategies are available for Heating, Ventilating, and Air Conditioning (HVAC) systems, which are responsible for the major loads in commercial and office buildings: the global temperature adjustment (GTA) [9-11], the system adjustment (SA) strategies [12], pre-cooling and pre-heating [13,14], duct static pressure control $[15,16]$, desiccant cooling and chiller water temperature control [17]. However, prior papers relevant to DR for buildings have generally relied on advanced building infrastructure and intense modification, which requires a high cost of investment. Many small buildings, especially in developing countries, still lack building energy management systems (BEMS), preventing them from joining the DR programs [9]. Moreover, the interior equipment of some buildings' air conditioners (ACs) cannot be modified due to this voiding their warranty. That is, only external equipment can be installed to control the ACs [18]. This poses challenges for implementing an automated DR system. Therefore, it is important to design an effective, simple, yet low-cost solution to popularize DR-capable buildings.

Another important concern in DR strategies for buildings is the impact of occupant thermal comfort during DR events. In the literature, there are significant differences made on the assumption of the way how people feel about their thermal comfort [19-22]. The most popular model is to use the Predicted Mean Vote (PMV) proposed by Fanger [23] to determine the thermal sensation of the occupants. The PMV index represents a "mean thermal sensation vote for a large group of building occupants for any given combination of thermal environmental variables, activity and clothing levels" [24]. An equation to calculate the PMV index uses four measurable quantities, air velocity, air temperature, mean radiant temperature and relative humidity, and two expected parameters, clothing and metabolism rate. The resulting index ranges from -3 (cold) to +3 (hot), where -0.5 to +0.5 is defined as thermal comfort zone by the ASHRAE Standard [20,25]. Despite its application and quantitative results based on controlled laboratory experiments, the PMV index does not always represent real situations in buildings since some of the important parameters 
that affect occupant thermal comfort are left out in real-world applications. Moreover, it requires continuous the measurement and estimation of the changing parameters needed for calculation. Hence, application in the real environment would require tedious work and more sensors. Another alternative method for assessing occupant thermal comfort is based on a field study by Dr. Thomas Bedford [26]. The model relies on the result of a field study in which the goal is to maintain people's ordinary living conditions. As concluded in [11], the PMV index method fails to account for the psychological aspect of the occupant's reaction to the changing indoor environment. In addition, the energy optimization is also taken into consideration. The total electric bill is reduced by heuristic-algorithm-based optimization models, as shown in [27-29]. The load scheduling and the short-term electric load forecasting model are also the major part of the optimization as proposed in [30,31]. Therefore, in this work, we will focus on applying the thermal comfort concept to maintain occupant's ordinary working conditions during DR events with these concerns.

To implement the DR measurements to customers, especially in the BEMS, integrating the DR devices into the existing certain load of the building, determining the peak demand reduction, and maintaining the thermal comfort of the occupants are the objectives of ours propose. With the minimum installation cost, an Internet of Things (IoT) device with control buttons for both manual and automatic operations will be taken into our consideration. Moreover, the energy management system (EMS) with a Human-Machine Interface (HMI) is used for determining the customer baseline and demand reduction. According to the building characteristics from the energy management system, the DR control strategy will play a role in maintaining the thermal comfort of the occupants.

As mention above, most of the DR literature focuses on the simulation and the proof of concept with adding more measurements. To encourage the building owner to be interested in the DR program, we present a practical power consumption reduction DR system design and implementation in a real environment without installing any additional measurements. We continue the work based on our previous paper [18] to incorporate an automated DR system. With the recent advancement in IoT devices become cheaper and more accessible, a solution for DR systems in small buildings can be implemented. We show that with simple and little modification to the existing ACs of the building, the reduction in the peak power consumption can be achieved while maintaining the thermal comfort of the occupants by installing only the computer server, embedded devices, and Ethernet network.

The rest of this paper is organized as follows. Section 2 describes a design of the DR system. In Section 3, the details of the proposed DR implementation are explained. The experimental results from the testing building and the discussion are given in Section 4 . Finally, the conclusion of the paper is drawn in Section 6.

\section{System Overview}

In this section, we present a summary of the system implemented in this work, which includes the system design, BEMS components, the DR system, and the building characteristics.

\subsection{System Design}

The system architecture is shown in Figure 1. The BEMS is separated into four layers of its responsibility: the market layer, operation layer, application layer, and field devices layer. Note that layers and their communication are not separated physically. A Human-Machine Interface (HMI), a Virtual Top Node (VTN), and the EMS have been developed in a single application. We develop the application with opened APIs for the ease of integration of new systems in the future. The details of each layer are as follows.

\subsubsection{The Market Layer}

The market layer consists of a Load Aggregator Management System (LAMS), which is responsible for sending and receiving information and commands between an energy market and its clients. The operations and details of the contract agreements between 
the energy market and supply and demand resource party are not the main focus in this work, and we assume that all the agreements have been completed before start of the DR program.

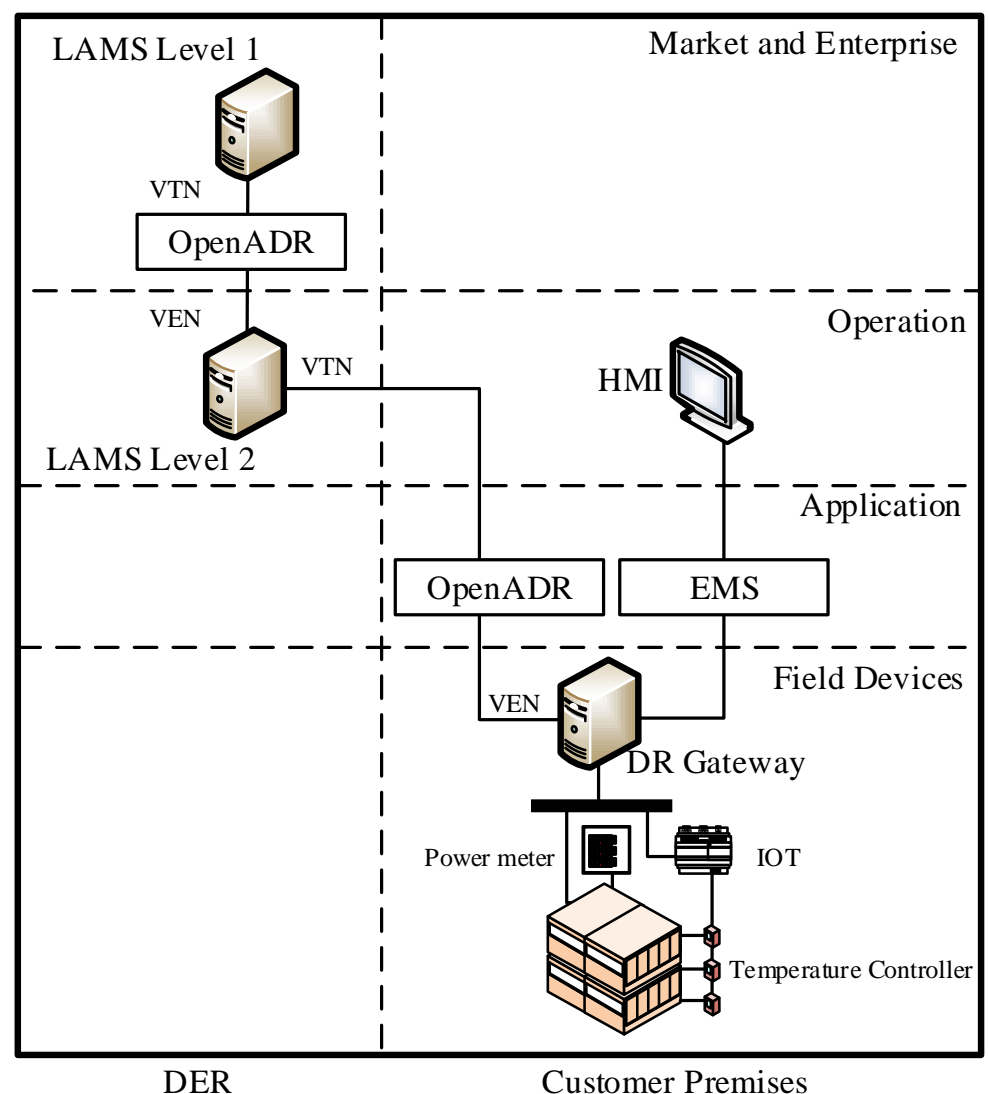

Figure 1. Overview of system architecture.

\subsubsection{The Operation Layer}

The operation layer is an interface for the user to set and control the system through the HMI, which connects to other systems / functions logically. There are two important function interactions with HMI: Virtual End Node (VEN) and EMS interactions. An HMIVEN interaction is primarily used for the user to accept or decline the DR event (Opt. in/Opt. out). An HMI-EMS interaction is for the user to setup the EMS to manage its electrical loads, e.g., AC systems.

\subsubsection{The Application Layer}

The application layer contains a software which is further separated into two virtual application logically: VEN and EMS. The VEN application is responsible for receiving and understanding the OpenADR2.0b protocol. The incoming message is deserialized to the object and is prompted for the necessary parameters to be extracted by the EMS. For the EMS application, the electrical load consumption is controlled to meet the requirements from the user-specified command/request. Note that VEN and EMS exchange data internally within the application. Figure 2 shows the two different protocols used in the developed software: OpenADR2.0b and MODBUS TCP/IP. Both protocols are separated into segments and encapsulated by TCP with a different port number. The packets are ready to be transmitted through a Network Interface Card (NIC) to an Ethernet switch. 


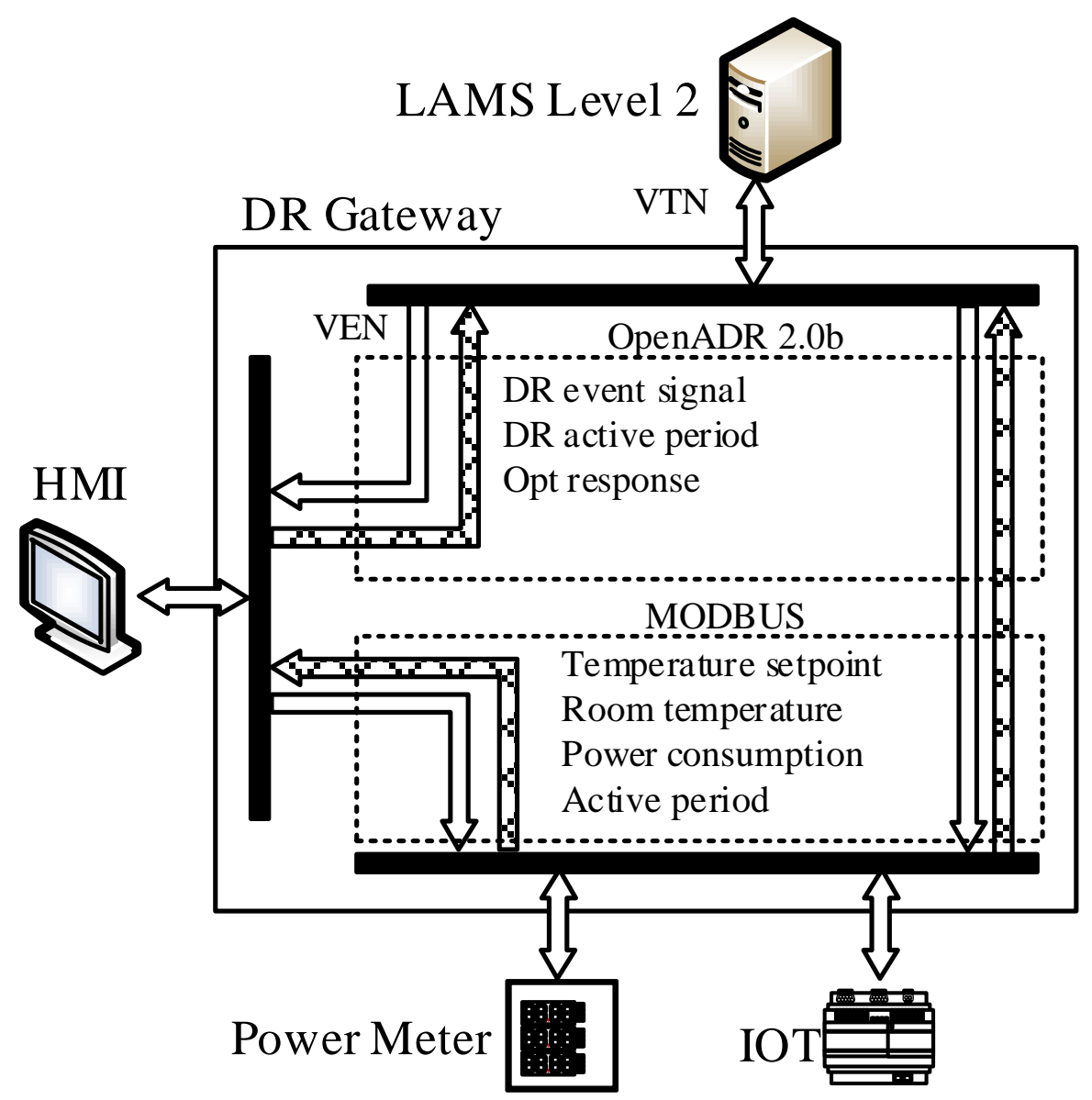

Figure 2. Internal architecture of the DR gateway and EMS.

\subsubsection{The Field Devices Layer}

The field devices layer consists of numbers of devices receiving commands from the EMS: communication devices, monitoring devices, and controllable devices. Figure 3 shows a physical diagram overview of the connected devices.

For communication devices, a TCP/IP network is used as a Local Area Network (LAN) for communication with the EMS. We set up a mesh WiFi to connect with all other devices. Each commercial Siemens IoT2040 gateway is used for communicating with a digital power meter in each zone/floor.

We use the digital power meters for gathering energy information as monitoring devices. To enable multiple-meter data reading, we connect the meter via RS485, which supports a multidrop connection. The existing power meters in the building were already installed with protocol converters.

For controllable devices, we modify the building's existing AC system temperature controller to connect with the Siemens IoT2040 gateway. This enables the temperature controller to receive a command from the EMS via MODBUS RTU, enabling load control and participation in the DR program.

The system consists of three main components: control devices, communication devices, and electrical loads. The list of equipment is shown in Table 1. AC systems are selected as the building electrical load for the DR program. According to the outdated $\mathrm{AC}$ system of the building, installing the new AC system to support the communication protocol and the automatic control will help the AC system to communicate with the utility or the load aggregator. However, we propose only installing the computer server, embedded devices, and Ethernet network to make the lowest investment cost in the DR solution. 


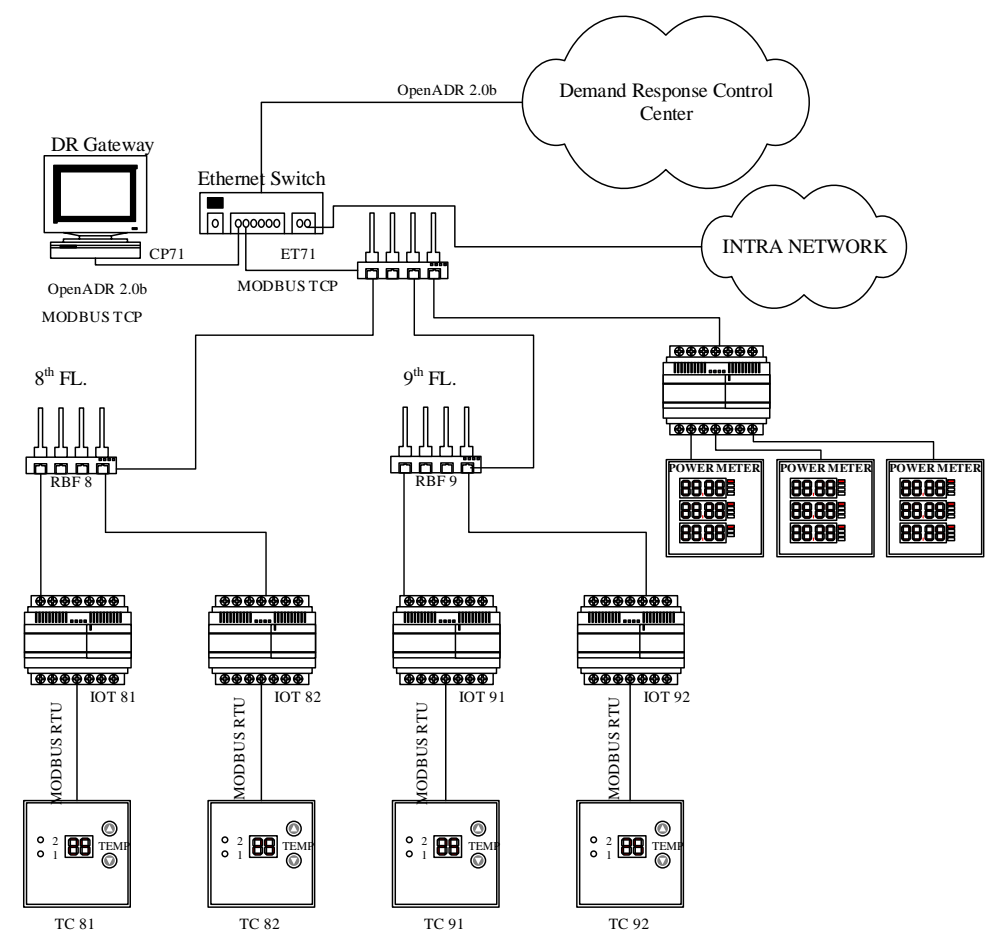

Figure 3. Overview of physical device connection diagram.

Table 1. List of BEMS equipment.

\begin{tabular}{cccc}
\hline Equipment & Detail/Sizing & Quantity & Remark \\
\hline AC81 & Trane $^{\circledR} 30 \mathrm{~kW}$ (PWC-81) & 1 & existing system \\
AC82 & Trane $^{\circledR} 30 \mathrm{~kW}$ (PWC-82) & 1 & existing system \\
AC92 & Trane $^{\circledR} 30 \mathrm{~kW}$ (PWC-92) & 1 & existing system \\
Power meter & SATEC EM133 & 3 & exiting system \\
DR gateway & Dell precision workstation PC & 1 & new investment \\
IoT device & Siemens SIMATIC IoT & 5 & new investment \\
Ethernet switch & Dell 8-gigabits port & 1 & new investment \\
Communication device & TP-Link deco mesh Wi-Fi & 3 & new investment \\
\hline
\end{tabular}

\subsection{Building Characteristics}

\subsubsection{Site Location}

The experiment building is located Metropolitan Electricity Authority (MEA) Rat Burana District Office, Bangkok, Thailand. The average outside temperature is $32{ }^{\circ} \mathrm{C}$. A typical indoor temperature for the office building is set to around $25^{\circ} \mathrm{C}$. We select three office rooms $(81,82,92)$ for the experiment, which are located on the eighth and ninth floors of the building. The existing ACs $\left(\right.$ Trane $\left.{ }^{\circledR}\right)$ are installed in separate areas and dedicated for each office room.

\subsubsection{Typical Energy Consumption Profile}

On working days, the building ACs operate from 7:15 to 15:30 with a one-hour shutdown during the office lunch break (12:00-13:00). Due to poor sizing and a lack of optimal operation of the ACs, the building staff turn on the ACs to full power at all times to avoid any hot temperature complaints. The total power consumption of the ACs is shown in Figure 4. The corresponding indoor temperature of each room is shown in Figure 5. Both the power consumption and the indoor room temperature charts depict the characteristics of this building. Even though the indoor room temperature was deceased down to $24^{\circ} \mathrm{C}$, the ACs were at full power operation. 

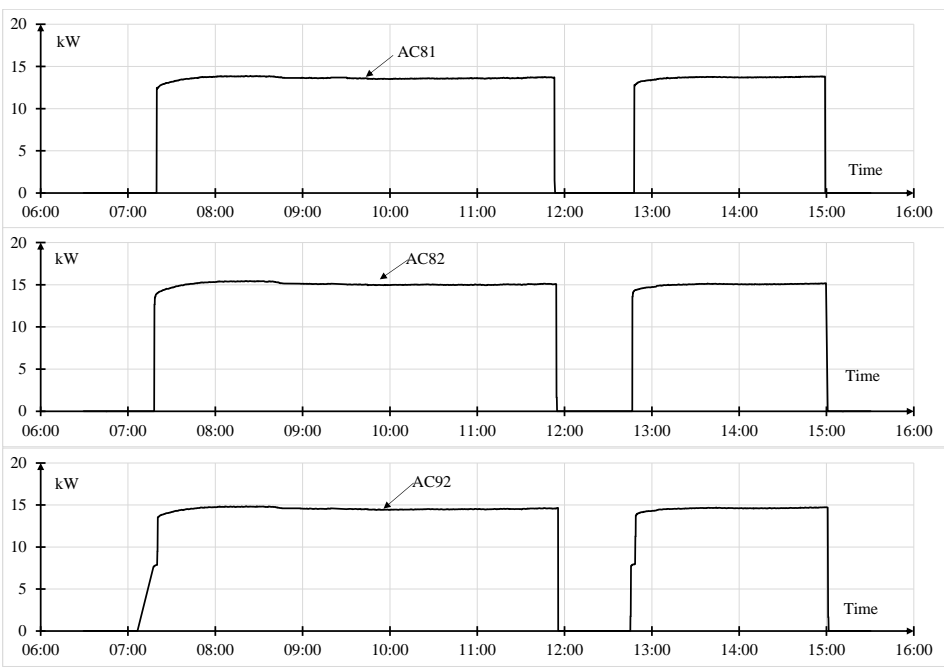

Figure 4. Typical total power consumption.
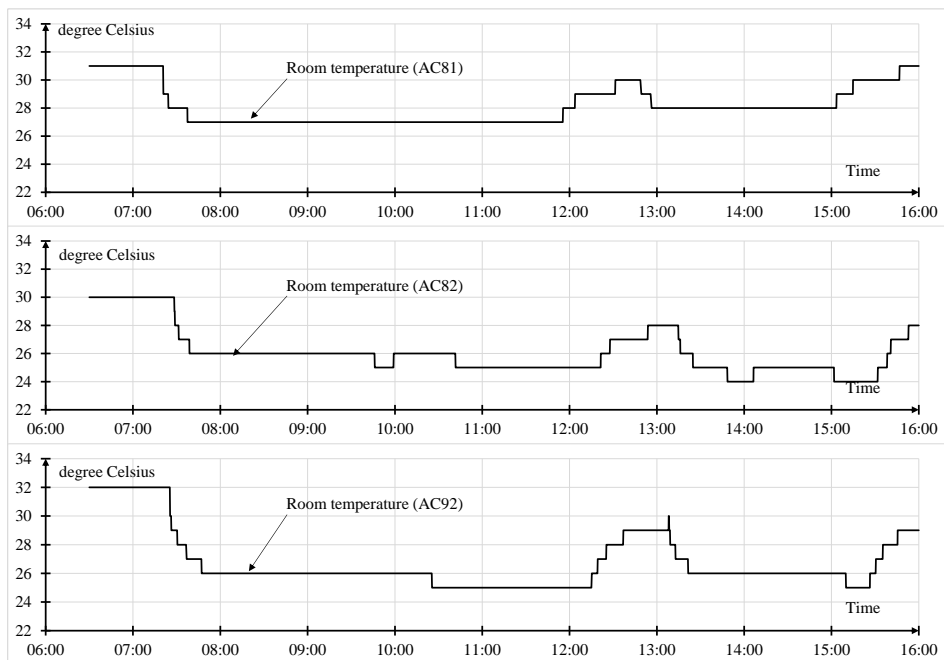

Figure 5. Typical room temperature.

\subsubsection{Limitation of the System Design}

Since the existing equipment and interior of the ACs cannot be modified because it would void the warranty, only external equipment can be installed for monitoring and controlling. Thus, we are limited to designing and implementing the BEMS without an advanced control scheme. Note that this situation covers a large portion of office buildings in Thailand and other developing countries.

\subsection{The Operation of the Demand Response System}

The diagram of the DR system is shown in Figure 3. We develop the DR client gateway using OpenADR2.0b to coordinate with the BEMS. The modified temperature controller of the $\mathrm{AC}$ system is used for responding to the DR event by setting appropriate temperature setpoints for each $\mathrm{AC}$ in each office room. We implemented the DR program using a signal from I-ON Communication Corporation (South Korea) that served as the demand response control center.

\subsubsection{Demand Response Event}

The ILP DR event is selected in this work to control the operation of ACs in the target office building, and the OpenADR2.0b is the main messaging protocol for the utility to 
communicate with downstream equipment during the DR event. The ILP uses incentives to persuade customers to reduce their energy consumption during a specified period of the day. The utility operator requests the amount energy reduction and duration in advance, and the customer can respond by accepting or declining the requests. During the DR event, the customers adjust their energy consumption to adhere the consumption limit.

\subsubsection{Determination of Customer Baseline}

To calculate the amount of energy saving, the Customer Baseline (CBL) is used as a reference. CBL can be regarded as the 'unbiased estimate of load'. It uses customers' historical load profiles to predict the amount of electricity that would normally be used before adopting the DR program. From the operator's view, it is hard to determine the exact amount of electricity reduction after a DR program is implemented. Therefore, determining the CBL is necessary to calculate the incentive for the participants. However, due to many factors that influence consumption patterns, various CBL calculation methods have been proposed in the literature [32-36] to improve accuracy. The MAX 5/10 method [36] is selected in this work due to it being simple and practically accurate.

\section{DR Implementation Details}

This section describes the actual hardware and control strategy implementation at the experiment site. We design our system by installing AC controllers in the existing AC rooms, as shown in Figures 6 and 7. Without modifying the interior of the ACs, a temperature setpoint monitor and controller (Figure 8) are installed externally. Thus, the setpoint of the AC can be changed according to the command from the BEMS, which in turn manages the energy consumption of the system and lowers the installation costs.

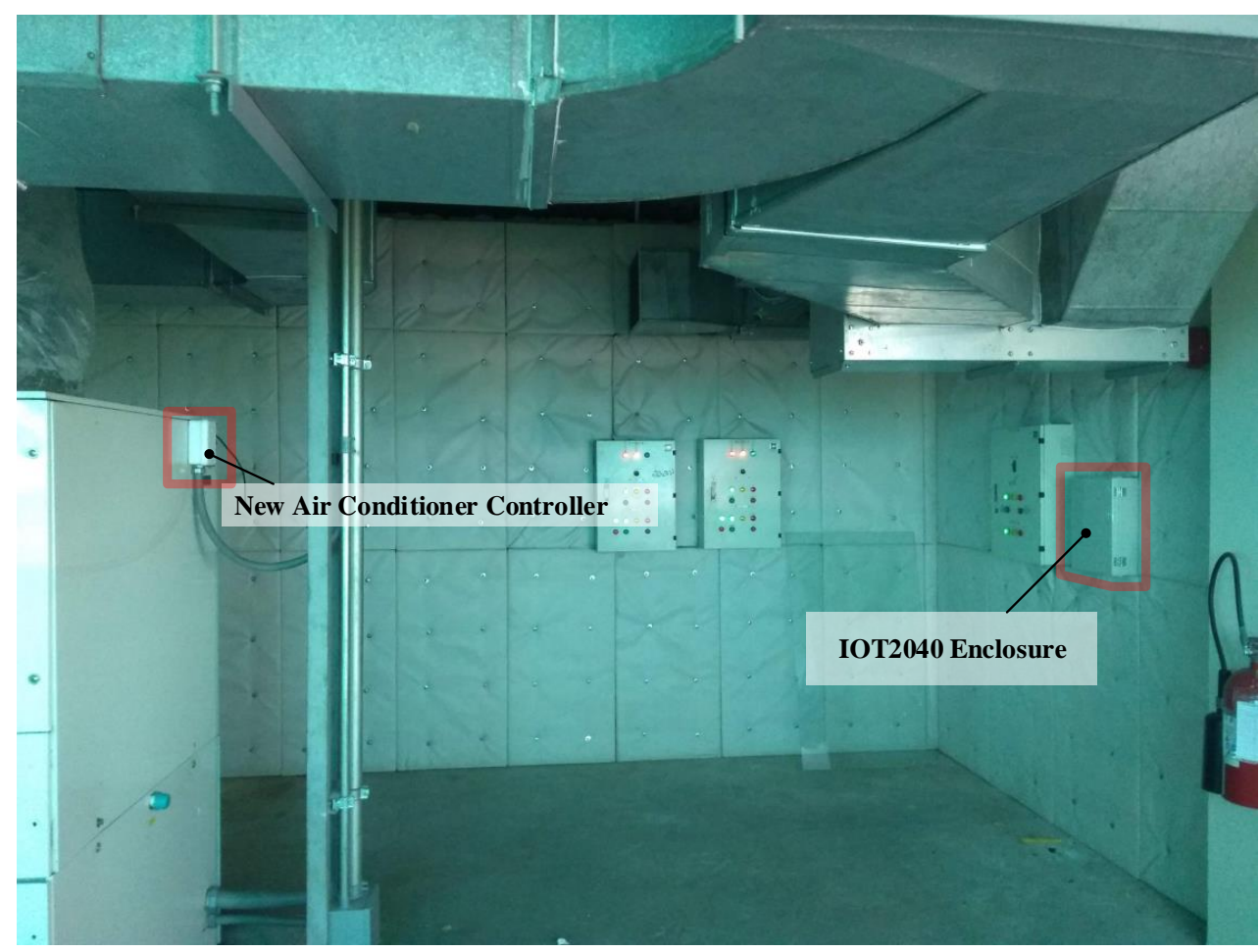

Figure 6. Air conditioning unit with IOT2040 installation. 


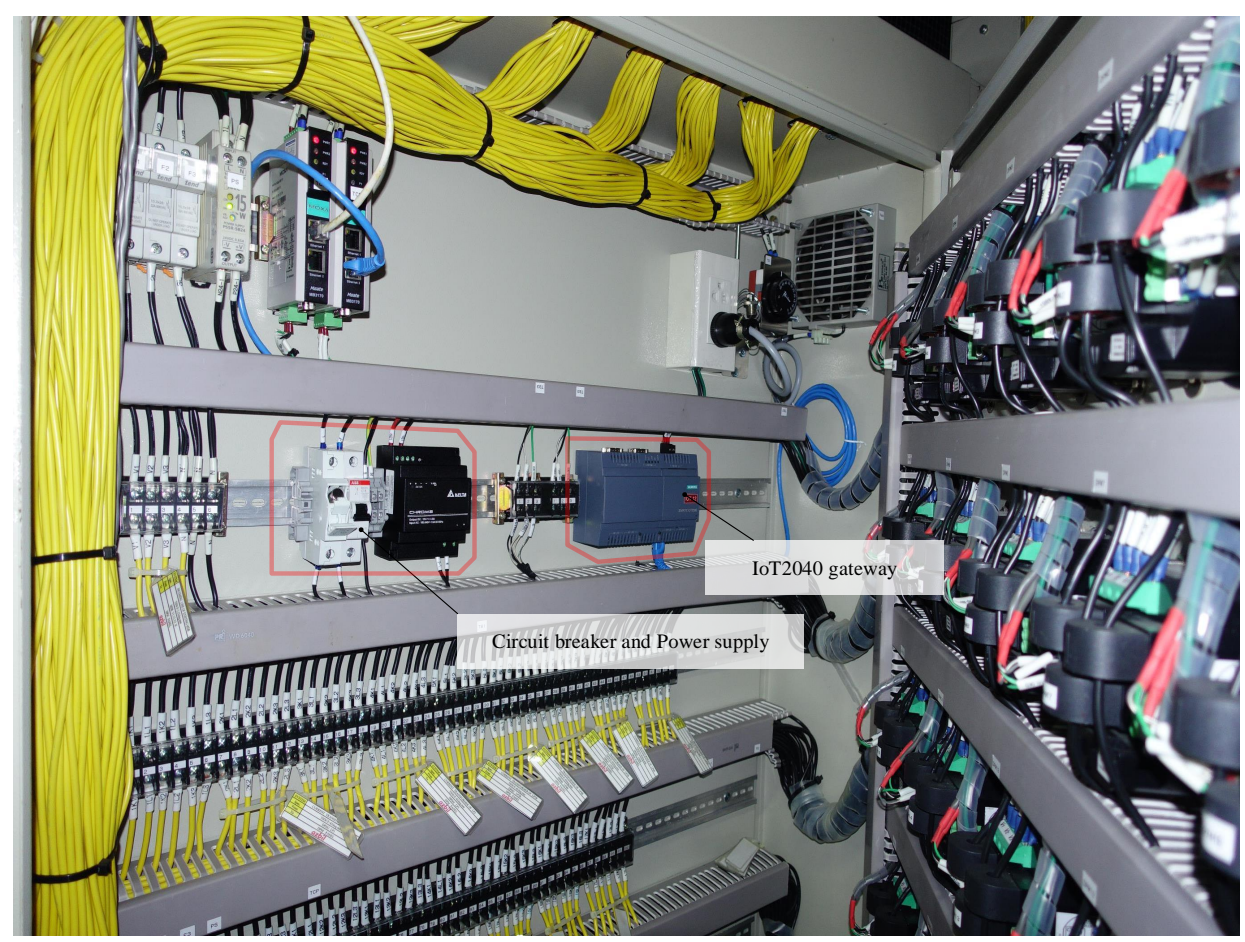

Figure 7. IoT2040 in the power meter enclosure.

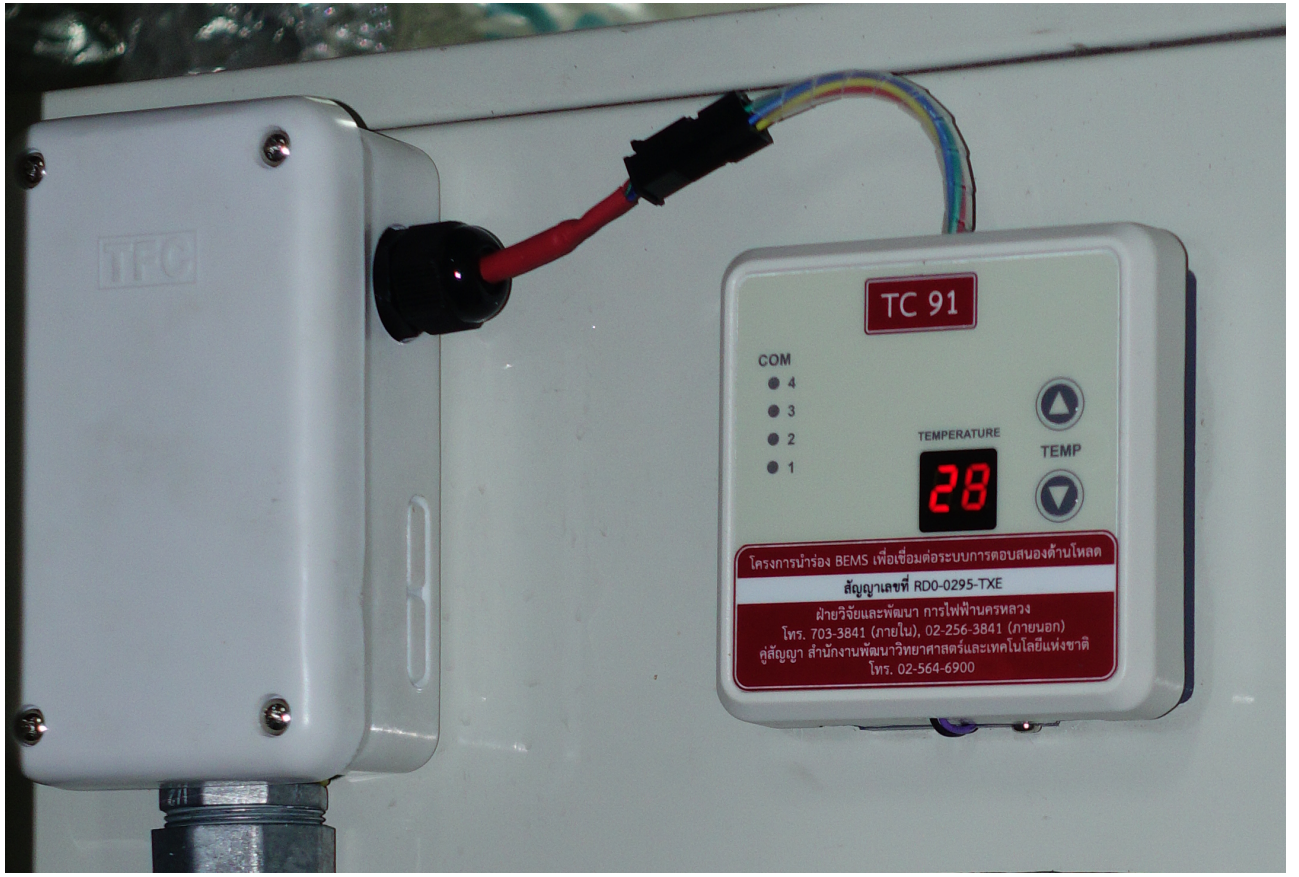

Figure 8. Temperature Controller (TC) unit.

\subsection{DR Request Accept/Decline Determination}

In order to execute the DR event, first, the BEMS needs to determine whether to accept or decline the day-ahead DR requests from the grid operator. The grid operator will send the DR request to the BEMS, including the amount of power reduction and the period of the event $[37,38]$. In our case, all ACs have three possible modes of operation, as shown in Table 2. In the original operation, all the ACs run at full capacity with two compressors. This resulting in the highest power consumption during office hours. However, with optimal control, we can manipulate the operation mode of the AC by scheduling lower power 
consumption modes while trying to minimize the increase in the room temperature and maintaining acceptable occupant comfort. Figure 9 shows a combination of the possible power consumption of three ACs with different operation modes. If we run only air blower mode, we can achieve maximum power consumption reduction, but this would quickly impact the room temperature to rise to unacceptable thermal discomfort. To maintain thermal comfort, the "one compressor" operation mode is suitable for the power reduction scenario as the room temperature would gradually rise and give enough time for the system to switch back to the "two compressors" mode before the occupants feel any thermal discomfort. Based on the aforementioned method, the BEMS determines whether to accept or decline the DR request by checking the power consumption scenarios. If there is an available match-up of the power reduction capacity and time duration, the BEMS accepts the DR request, otherwise, it declines. After accepting the DR request, the BEMS will schedule the operation of the ACs as presented in the following section.

Table 2. Operation modes and power consumption of air-conditioning units.

\begin{tabular}{cccc}
\hline $\begin{array}{c}\text { Air Conditioner } \\
\text { Code }\end{array}$ & Air Blower (kW) & One Compressor (kW) & $\begin{array}{c}\text { Two Compressors } \\
(\mathbf{k W})\end{array}$ \\
\hline PWC-81 & 1.9 & 7.3 & 12.7 \\
\hline PWC-82 & 1.9 & 7.3 & 13.5 \\
\hline PWC-92 & 1.8 & 7.5 & 13.1 \\
\hline Condition & - & Return Temperature -1 & Return Temperature \\
\hline
\end{tabular}

\subsection{DR Control Strategy}

According to the demand response policy in Thailand, the DRCC will send a request for $15 \mathrm{~min}, 1 \mathrm{~h}$, or $24 \mathrm{~h}$ ahead to the participants to ask if they will join the program.

To manage the power consumption of the AC during a DR program, we have to understand the characteristics of the ACs in each room. Specifically, each AC consists of two compressors and one air blower, and we have to study the power consumption of each device to make scenarios for the DR program. The power consumption and the condition for turning one compressor on or off can be seen from the scenarios in Figure 9.

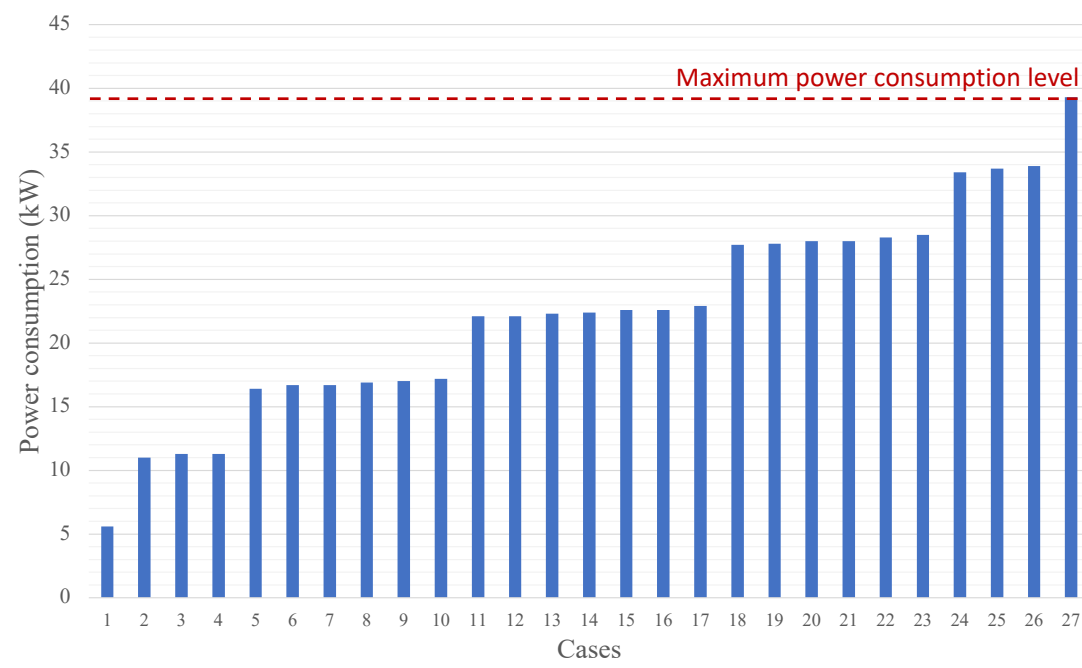

Figure 9. Difference scenario of total power consumption of ACs.

We manage the indoor temperature in the trial rooms by two compressors, and the temperature setpoint is set to $19^{\circ} \mathrm{C}$ during working hours. That means every compressor is fully operating when working staff work in the experiment building, and the indoor temperature during working hours can be seen in Figure 10. 


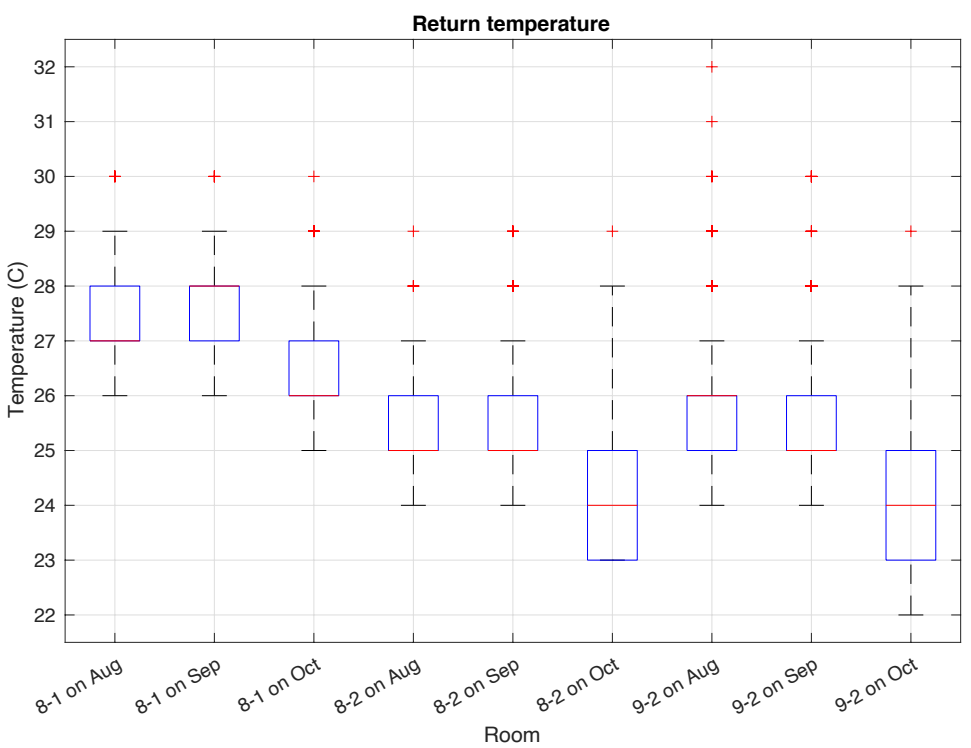

Figure 10. Return temperature in room 81, 82, and 92 from August to October 2020 in the test building.

In Figure 10, the boxplot shows the return temperature and room temperature in rooms 81, 82, and 92 from August to October in 2020. The blue boxes are the return temperature between the 25 th and 75 th percentiles, and the red lines are the median value of the return temperature. Accordingly, the occupants in room 81 are working at a temperature around 26 to $28{ }^{\circ} \mathrm{C}$. The occupants in rooms 82 and 92 are working at temperatures around 24 to $26^{\circ} \mathrm{C}$. Therefore, this study attempts to manage the room temperature according to the room temperature range in Figure 10 to satisfy the occupants' comfort during the DR event. Moreover, we have reported that the occupants in the building will feel hot and start complaining about the room temperature when the return temperature is higher than $28^{\circ} \mathrm{C}$. Then, our control strategy sets the upper limit of the room temperature $T_{r, \text { limit }}$ to $28^{\circ} \mathrm{C}$ to avoid this complaint from the occupants of the building.

During the experiment, when the temperature setpoint is set to be such value, we notice the hysteresis loop control in the room temperature and power consumption. Specifically, the AC system turns on two compressors when the indoor temperature is higher than that setpoint and turns on one compressor when the indoor temperature is lower than that setpoint, as shown in Figure 11.

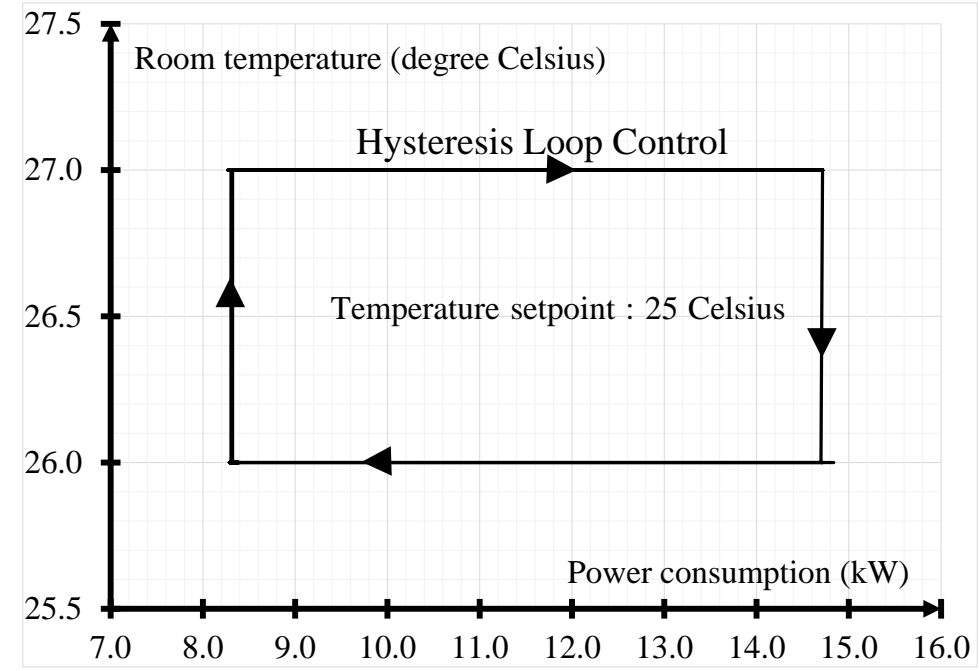

Figure 11. Room temperature and power consumption of AC hysteresis loop in room 92. 
Figure 11 shows the relation between the room temperature and the power consumption of $\mathrm{AC}$ in room 92 when the temperature setpoint is set to $25{ }^{\circ} \mathrm{C}$, where the $\mathrm{x}$-axis is the power consumption of $\mathrm{AC}$, and the $\mathrm{y}$-axis is the room temperature. This figure represents that when the room temperature is higher than $27^{\circ} \mathrm{C}$, two compressors are turned on, and the power consumption is $14.8 \mathrm{~kW}$. On the other hand, when the room temperature is lower than $26^{\circ} \mathrm{C}$, one compressor is turned on, and the power consumption is around $8.3 \mathrm{~kW}$. We found that this behavior continues for a while during the morning and afternoon periods. Therefore, the feasible temperature setpoint can be calculated by Equation (1):

$$
T_{s p}=T_{R, \min }+t_{\text {uncertainty }}
$$

In Equation (1), $T_{s p}$ is a feasible temperature setpoint that can be used for controlling a room temperature hysteresis loop. $T_{R, \min }$ is the lowest room temperature when the ACs in the room are fully operating, and $t_{\text {uncertainty }}$ is the temperature setpoint uncertainty of the temperature controller, which is the unique value for each temperature controller. As a result, we acquired $t_{\text {uncertainty }}$ being equal to " -1 " from the experiment.

\subsection{Determination of AC Temperature Setpoint}

To predict the day-ahead temperature setpoint, we leverage the neural network technique that is widely used to estimate the future value, such as Room temperature $[39,40]$ and Load forecast [41,42]. Therefore, we developed the temperature setpoint prediction model by a classification neural network. Note that this study considers the action plan for the DR program's participants when they receive the DR request. Then, the temperature setpoint prediction is just a part of this action plan. Hence, this work does not take the method for designing the best model into consideration. This will be a future study.

For inputs of the prediction model, we suppose the outdoor temperature, the outdoor humidity, the weather condition, and the time of day are features to determine the temperature setpoint. For the outdoor temperature, outdoor humidity, and weather condition features, Mustafaraj et al. show that the indoor temperature is related to the outdoor temperature, outdoor humidity, weather conditions, and AC parameters [39]. Due to the limitation of the existing building, we denote that our system has only the temperature setpoint controllers, and we have no controllers to adjust another AC parameter. This study, consequently, will use the forecast information about outdoor temperature, outdoor humidity, and weather conditions to predict the temperature setpoint. We obtained the outdoor temperature, the outdoor humidity, and the weather conditions from weather forecasting services such as Accuweather and Wunderground.

Furthermore, the room temperature in the building used in this study is spatiotemporal. Specifically, the rooms located on the east side of the building are hotter than the rooms on the other side in the morning, while the rooms located on the west side of the building are hotter than the rooms on the other side in the afternoon.

For output, we calculate the feasible temperature setpoint $T_{s p, h h}$ for each hour, where $h$ is the time of day for each room based on the indoor temperature by Equation (1) with $t_{\text {uncertainty }}$ is " -1 ". Moreover, we found that we can use the same setpoint for two or more hours, but the setpoint used in the morning can be different from the setpoint used in the afternoon. For each day, we divide the feasible temperature setpoint into two periods: morning and afternoon. Then, we select the most frequent of $T_{s p, h h}, \forall h h$ in the same groups by the MODE function, a statistical function, to be the representative feasible temperature setpoint $T_{s p, r e p, g}$ as the setpoint prediction model's output of group $g \in\{$ morning, afternoon\}, as shown in Figure 12.

In Figure 12, the building is occupied by the office workers from 7:00 to 15:59. The time of day $h h \in\{7,8, \ldots, 15\}$ represents the hour period of time from $h h: 00$ to $h h: 59$. $T_{O, h h}$ $H_{O, h h}, W_{h h}$, and $T_{R, h h}$ are the outdoor temperature, the outdoor humidity, the weather conditions, and the room temperature at the time of day $h h$, respectively. Next, the feasible temperature setpoint $T_{s p, h h}$ at time $h h$ can be calculated by using Equation (1) with $t_{\text {uncertainty }}=-1$. Hence, we can use the most common value of a set of feasible temperature 
setpoints $\left\{T_{s p, 7}, T_{s p, 8}, \ldots, T_{s p, 11}\right\}$ to be the representative temperature setpoint in the morning $T_{s p, r e p, \text { morning, }}$ and use the most frequent value of a set of feasible temperature setpoints $\left\{T_{s p, 12}, T_{s p, 13}, \ldots, T_{s p, 15}\right\}$ to be the representative temperature setpoint in the afternoon $T_{\text {sp,rep,afternoon }}$.

\begin{tabular}{|c|c|c|c|c|c|c|c|c|c|}
\hline Time & 7am & 8am & 9am & 10am & $11 \mathrm{am}$ & $12 \mathrm{pm}$ & $1 \mathrm{pm}$ & $2 \mathrm{pm}$ & $3 p m$ \\
\hline Time of Day & 7 & 8 & 9 & 10 & 11 & 12 & 13 & 14 & 15 \\
\hline Outdoor Temp. & $T_{0,7}$ & $T_{0,8}$ & $T_{0,9}$ & $T_{0,10}$ & To,11 & To,12 & $T_{0,13}$ & $T_{0,14}$ & To,15 \\
\hline Outdoor Humid & $\mathrm{H}_{0,7}$ & $\mathrm{H}_{\mathrm{o}, 8}$ & $\mathrm{H}_{0,9}$ & $\mathrm{H}_{0,10}$ & $\mathrm{H}_{\mathrm{o}, 11}$ & $\mathrm{H}_{0,12}$ & $\mathrm{H}_{0,13}$ & $\mathrm{Ho}_{0,14}$ & $\mathrm{Ho}_{0,15}$ \\
\hline Weather & $W_{7}$ & $W_{8}$ & $W_{9}$ & $W_{10}$ & $W_{11}$ & $W_{12}$ & $W_{13}$ & $W_{14}$ & $W_{15}$ \\
\hline Indoor Temp & $\mathrm{T}_{\mathrm{R}, 7}$ & $\mathrm{~T}_{\mathrm{R}, 8}$ & $\mathrm{~T}_{\mathrm{R}, 9}$ & $T_{R, 10}$ & $\mathrm{~T}_{\mathrm{R}, 11}$ & $\mathrm{~T}_{\mathrm{R}, 12}$ & $\mathrm{~T}_{\mathrm{R}, 13}$ & $\mathrm{~T}_{\mathrm{R}, 14}$ & $\mathrm{~T}_{\mathrm{R}, 15}$ \\
\hline Feasible Setpoint & $\mathrm{T}_{\mathrm{sp}, 7}$ & & $\mathrm{~T}_{\mathrm{sp}, 9}$ & $\mathrm{~T}_{\mathrm{sp}, 10}$ & $\mathrm{~T}_{\mathrm{sp}, 11}$ & $\mathrm{~T}_{\mathrm{sp}, 12}$ & & $\mathrm{~T}_{\mathrm{sp}, 14}$ & $\mathrm{~T}_{\mathrm{sp}, 15}$ \\
\hline \multicolumn{4}{|c|}{$T_{\text {sp }, \text { rep,morning }}=\operatorname{Mode}\left(T_{s p, 7}, T_{s p, 8}, \ldots, T_{s p, 11}\right)$} & \multicolumn{6}{|c|}{$T_{s p, r e p, a f t e r n o o n}=\operatorname{Mode}\left(T_{s p, 12}, T_{s p, 13}, \ldots, T_{s p, 15}\right)$} \\
\hline Time of Day & 7 & 8 & 9 & 10 & 11 & 12 & 13 & 14 & 15 \\
\hline Outdoor Temp. & $\mathrm{T}_{0,7}$ & $T_{0,8}$ & $T_{0,9}$ & $T_{0,10}$ & To,11 & To,12 & $\mathrm{T}_{0,13}$ & To,14 & $T_{0,15}$ \\
\hline Outdoor Humid & $\mathrm{H}_{0,7}$ & $\mathrm{H}_{\mathrm{o}, 8}$ & $\mathrm{H}_{0,9}$ & $\mathrm{H}_{0,10}$ & $\mathrm{Ho}_{0,11}$ & $\mathrm{H}_{\mathrm{o}, 12}$ & $\mathrm{H}_{0,13}$ & $\mathrm{Ho}_{0,14}$ & $\mathrm{Ho}_{0,15}$ \\
\hline Weather & $\mathrm{W}_{7}$ & $W_{8}$ & $W_{9}$ & $W_{10}$ & $W_{11}$ & $W_{12}$ & $\mathrm{~W}_{13}$ & $W_{14}$ & $W_{15}$ \\
\hline $\begin{array}{c}\text { Representative } \\
\text { Setpoint }\end{array}$ & \multicolumn{5}{|c|}{$\mathbf{T}_{\text {sp,rep,morning }}$} & \multicolumn{4}{|c|}{$\mathbf{T}_{\text {sp,rep,afternoon }}$} \\
\hline
\end{tabular}

Figure 12. Temperature setpoint calculation for training the setpoint prediction model.

For the temperature setpoint prediction model, the prediction model consists of three fully connected layers (FC1, FC2, and FC3), and layer 1's size, layer 2's size, and layer 3 's size are 256, 128, and 64, respectively. We apply the dropout technique [43] with a $20 \%$ dropout rate for preventing overfitting between layer 2 and layer 3 . We also implement the ReLu activation [44] in layer 3. This model uses the softmax function to be the output of classification, and the number of softmax functions is the number of classes of setpoints. Finally, we train the model by using the Adaptive Moment Estimation (Adam) optimizer [45]. The temperature setpoint prediction model can be represented by Figure 13. This proposed method trains the model offline. Hence, the training process does not affect the processing time of the DR management procedure. A summary of the DR event accept/decline decisions and temperature setpoint control diagrams are shown in Figures 14 and 15, respectively.

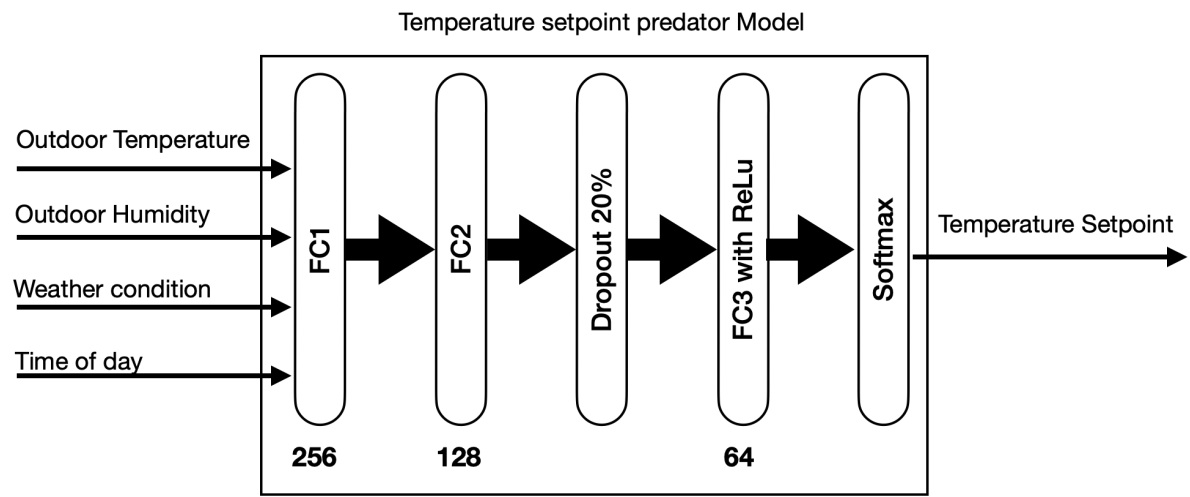

Figure 13. The setpoint prediction model, where FC is a fully connected layer. 


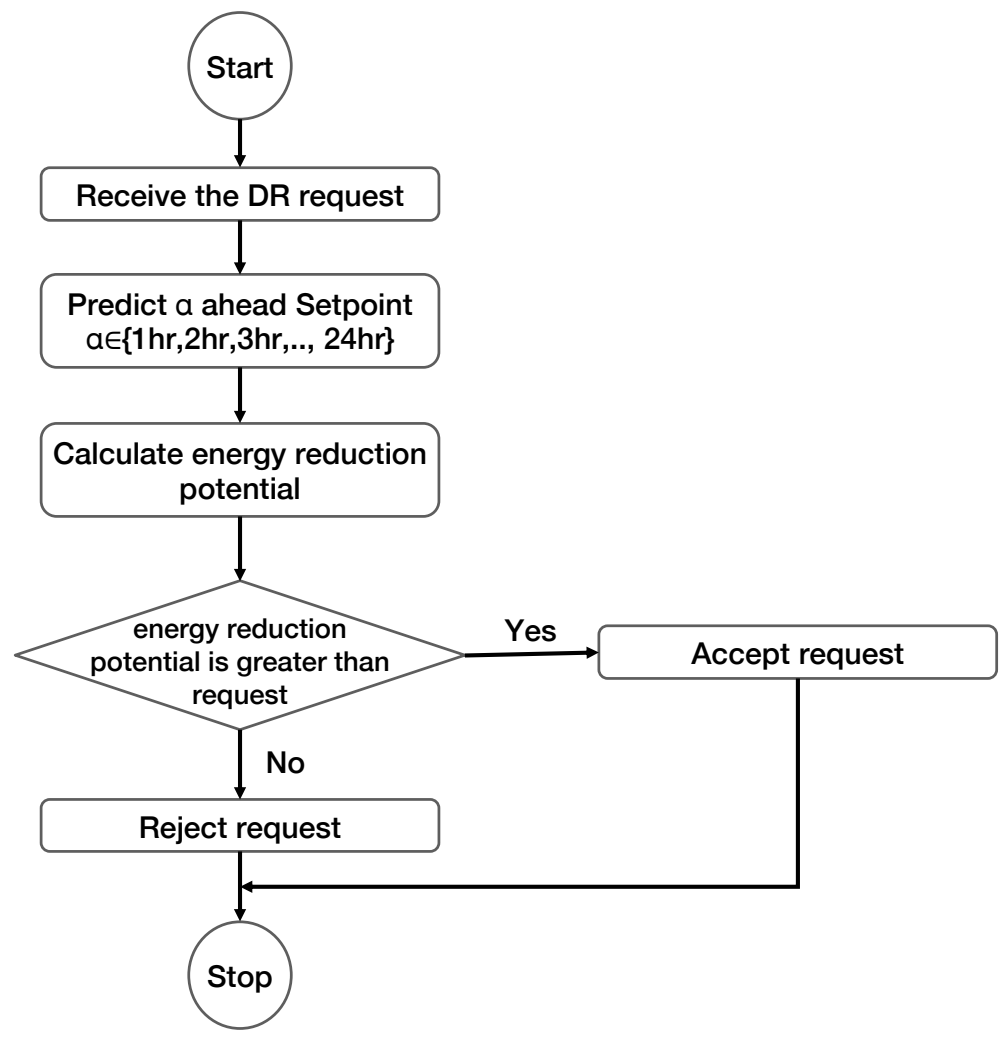

Figure 14. A diagram of a DR event accept/decline decision.

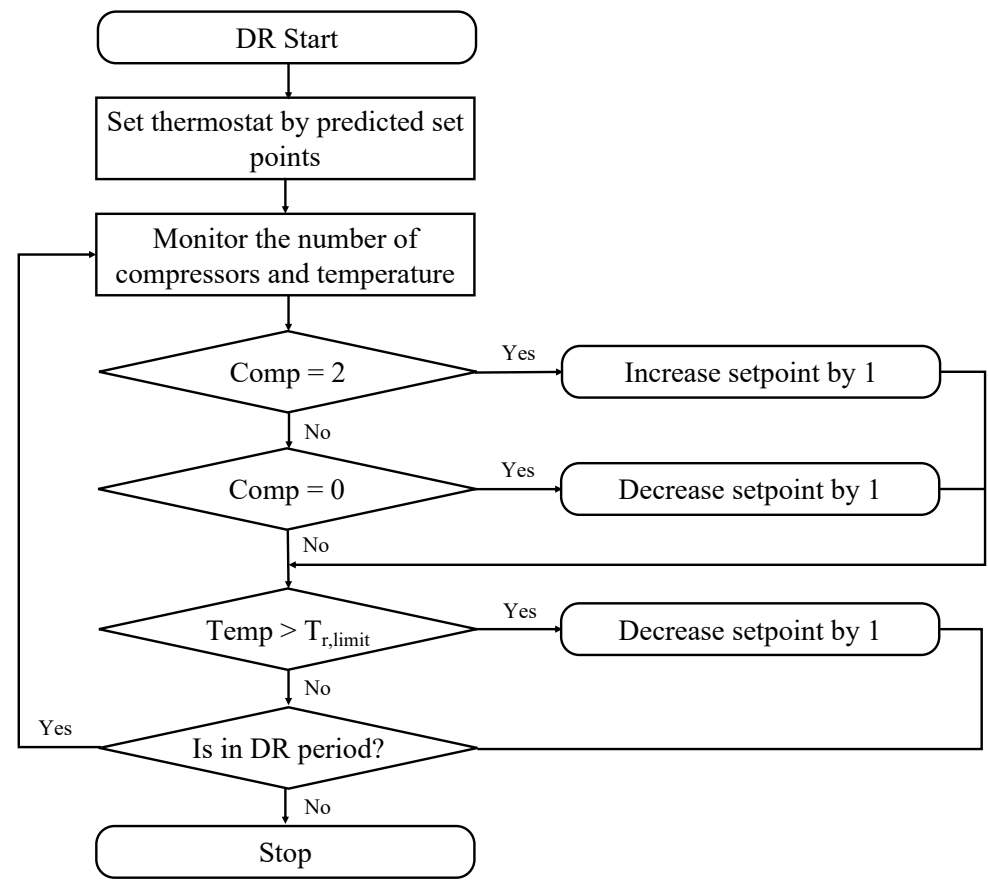

Figure 15. A diagram of temperature setpoint control during DR event.

\section{Experimental Results and Discussion}

\subsection{Experiment on the Temperature Setpoint Estimation}

The research team conducted the experiment for collecting the indoor temperature in rooms 81, 82, and 92 from 1 August 2020 to 31 October 2020. During the experiment, the temperature setpoints for each room were set to $19^{\circ} \mathrm{C}$ by the building management staff. We found that the indoor temperature in each room is around $23-28{ }^{\circ} \mathrm{C}$, as shown in 
Figure 10. The IoT device, the Siemens SIMATIC IoT2040, collects the indoor temperature every $15 \mathrm{~min}$ in three rooms simultaneously. Then, the collected data are discarded in room temperature data when no compressor operates. Next, we assume that the room temperature in the filtered dataset is the return temperature because the setpoint is $19^{\circ} \mathrm{C}$ during data correction. For each day in the dataset, we calculate the feasible temperature setpoint (1) for each time of day, and separate the data into a morning period and an afternoon period. In each period, we applied a MODE function and a statistical function to calculate the predicted setpoint, as in Figure 16.

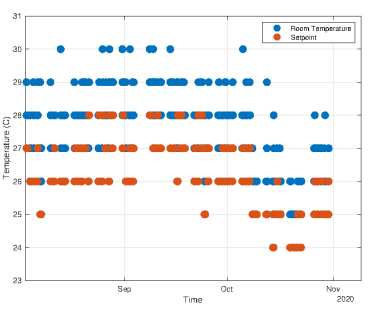

(a)

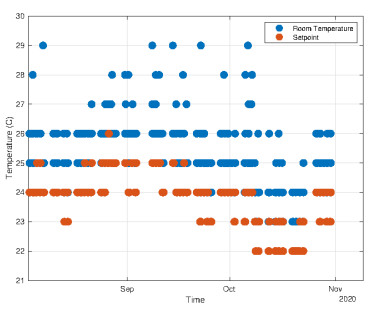

(b)

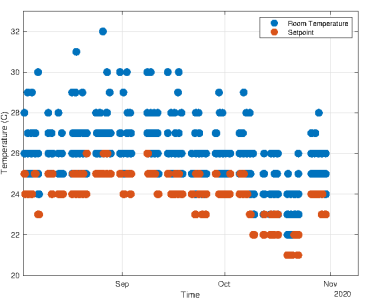

(c)

Figure 16. Return temperature and temperature setpoint for each room in the testing dataset. (a) Return temperature and temperature setpoint of room 81. (b) Return temperature and temperature setpoint of room 82. (c) Return temperature and temperature setpoint of room 92.

Finally, we divide the dataset into a training dataset and a testing dataset by $70 \%$ and $30 \%$, respectively. In summary, the number of samples for collected data, training data, and testing data are summarized in Table 3.

Table 3. The number of samples recorded in our experiment.

\begin{tabular}{cccc}
\hline \multirow{2}{*}{ Criteria } & \multicolumn{3}{c}{ The Number of Samples } \\
\cline { 2 - 4 } & Room 81 & Room 82 & Room 92 \\
\hline Total & 8831 & 8831 & 8831 \\
\hline ACs operating & 1687 & 1700 & 1712 \\
\hline Training dataset & 1181 & 1190 & 1199 \\
\hline Testing dataset & 506 & 510 & 513 \\
\hline
\end{tabular}

The proposed setpoint prediction model is implemented by using MATLAB version 2021b and Deep Learning Toolbox on Intel Core I5-7360U @ 2.3 GHz with 8 GB RAM machine. Accordingly, the structure of the model can be seen in Table 4 .

In Table 4 , layer no. 1 is configured for the four inputs with the z-score normalization. Layers no. 2-6 and layer no. 8 are configured as in Figure 13. In this paper, the temperature setpoints in the dataset are classified into six classes $\left(23^{\circ} \mathrm{C}, 24^{\circ} \mathrm{C}, 25^{\circ} \mathrm{C}, 26^{\circ} \mathrm{C}, 27^{\circ} \mathrm{C}\right.$, and $28{ }^{\circ} \mathrm{C}$ ); then, layer no. 6 is configured by six fully connected layers. Finally, we use the cross entropy loss function for the classification output in layer no. 9. After that, we train the temperature setpoint prediction model by using the Adam optimizer [45] with the parameters seen in Table 5. 
Table 4. Configuration of the temperature setpoint prediction model.

\begin{tabular}{cll}
\hline Layer No. & Layer Name & Configuration \\
\hline 1 & Feature Input & 4 features with z-score normalization \\
\hline 2 & Fully Connected & 256 fully connected layer \\
\hline 3 & Fully Connected & 128 fully connected layer \\
\hline 4 & Dropout & $20 \%$ dropout \\
\hline 5 & Fully Connected & 64 fully connected layer \\
\hline 6 & ReLU & - \\
\hline 7 & Fully Connected & 6 fully connected layer \\
\hline 8 & Softmax & - \\
\hline 9 & Classification Output & Cross Entropy loss function \\
\hline
\end{tabular}

Table 5. Parameters and values for Adam optimizer used for training the temperature setpoint prediction model.

\begin{tabular}{lc}
\hline \multicolumn{1}{c}{ Parameter } & Value \\
\hline Decay rate of gradient moving average $(\beta 1)$ & 0.9 \\
\hline Decay rate of squared gradient moving average $(\beta 2)$ & 0.999 \\
\hline Epsilon $\epsilon$ & $1.0 \times 10^{-8}$ \\
\hline Initial learning rate & 0.005 \\
\hline Gradient Threshold Method & L2-norm \\
\hline Gradient Threshold & 1 \\
\hline Factor for L2 regularizer (weight decay) & $1.0 \times 10^{-4}$ \\
\hline Max Epochs & 500 \\
\hline
\end{tabular}

Next, we train the model by the training dataset and verify the model by the test dataset. Consequently, the results in Figure 17a-c show the predicted results compared to the ground-truth and the temperature setpoints in the testing dataset for rooms 81,82 , and 92. It can be seen that each model can predict the estimated setpoints, red circles, which are similar to the ground-truth setpoints, blue circles.

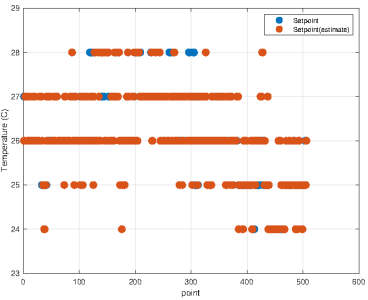

(a)

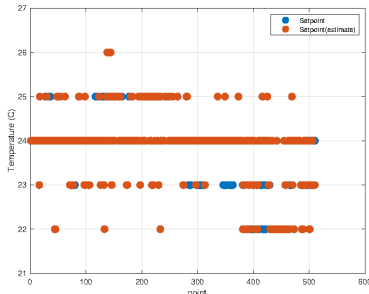

(b)

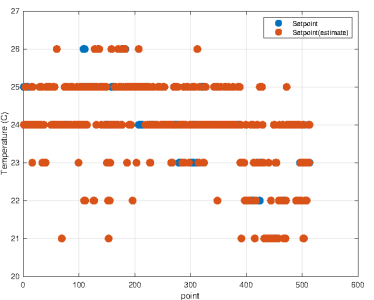

(c)

Figure 17. Ground-truth temperature setpoint and estimated temperature setpoint for each room in the testing dataset. (a) Ground-truth temperature setpoint and estimated temperature setpoint of room 81. (b) Ground-truth temperature setpoint and estimated temperature setpoint of room 82. (c) Ground-truth temperature setpoint and estimated temperature setpoint of room 92.

We train and evaluate the temperature setpoint prediction model 20 times, and the accuracy of each model can be seen in Figure 18a. 


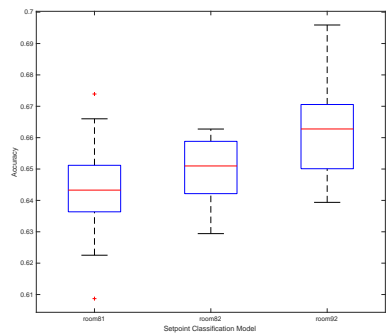

(a)

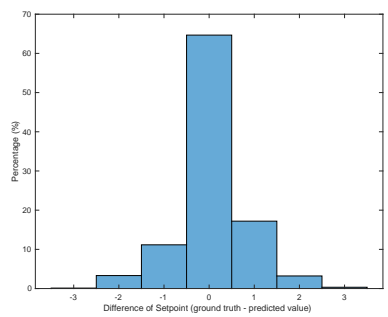

(c)

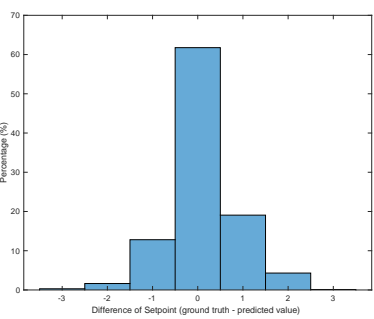

(b)

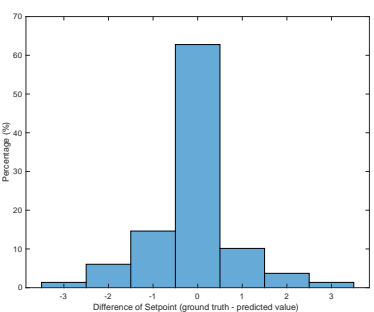

(d)

Figure 18. Accuracy and Difference of the temperature setpoint prediction models compared to the ground-truth in the test dataset. (a) Accuracy of the temperature setpoint prediction models. (b) Histogram of the difference between the ground-truth setpoint and predicted setpoint of the temperature setpoint prediction models for room 81. (c) Histogram of the difference between the ground-truth setpoint and predicted setpoint of the temperature setpoint prediction models for room 82. (d) Histogram of the difference between the ground-truth setpoint and predicted setpoint of the temperature setpoint prediction models for room 92.

In summary, the accuracies in Figure 18a of the model are $65.2 \%$ for room $81,63.53 \%$ for room 82 , and $66.73 \%$ for room 92 . Although the accuracy is not high, we found that the predicted values are close to the ground-truth values, as in Figure $18 \mathrm{~b}-\mathrm{d}$. As a result, the temperature setpoint prediction models have enough accuracy for estimating the energy reduction potential for deciding the response to the DR request.

\subsection{Experiment on the DR Control}

For the experiment, we assume a DR event request was sent from the utility operator on 11 October 2021 (day-ahead) with $19 \mathrm{~kW}$ power reduction from 8 a.m. to 3 p.m. The BEMS then made a decision on accepting or declining the request based on the diagram in Figure 14. In our demonstrated experiment, the DR request was accepted, and the BEMS replied to the request from the utility operator. In the following day, we tested the proposed DR method on 12 October 2021. Figure 19 shows the power consumption of the AC units and the CBL in each room. At 6:45 a.m., the building staff turned on the ACs as normal operation. Both the CBL and actual power consumption increased to $44.78 \mathrm{~kW}$. When the DR event started at 8 a.m., the setpoints of all AC units were set to new setpoints according to Equation (1), forcing the ACs to operate with one compressor. As a result, power consumption was reduced by $19.80 \mathrm{~kW}$, and all ACs maintained total power consumption at around $24.98 \mathrm{~kW}$, which is below the DR request. From 8 a.m. to 3 p.m. the power consumption is maintained as we monitored and kept the room temperature below $28^{\circ} \mathrm{C}$. The DR event ended at 3 p.m., which is also the end of office hours, and all ACs were turned off. The corresponding temperature for each room during the DR event is shown in Figure 20. The temperature was successfully kept below $28^{\circ} \mathrm{C}$ by controlling the power consumption of the $\mathrm{AC}$ via temperature setpoint to keep a comfortable temperature for the occupants. 

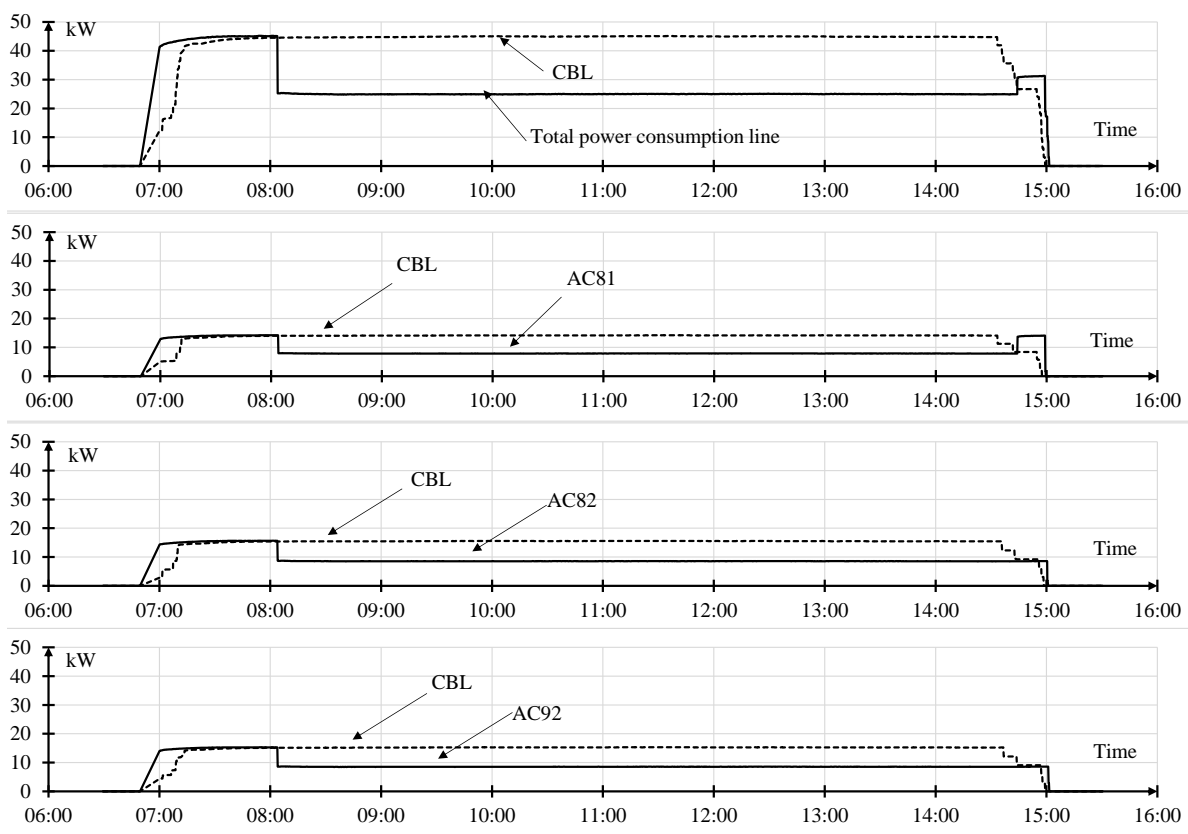

Figure 19. Power consumption and CBL on 12 October 2021.
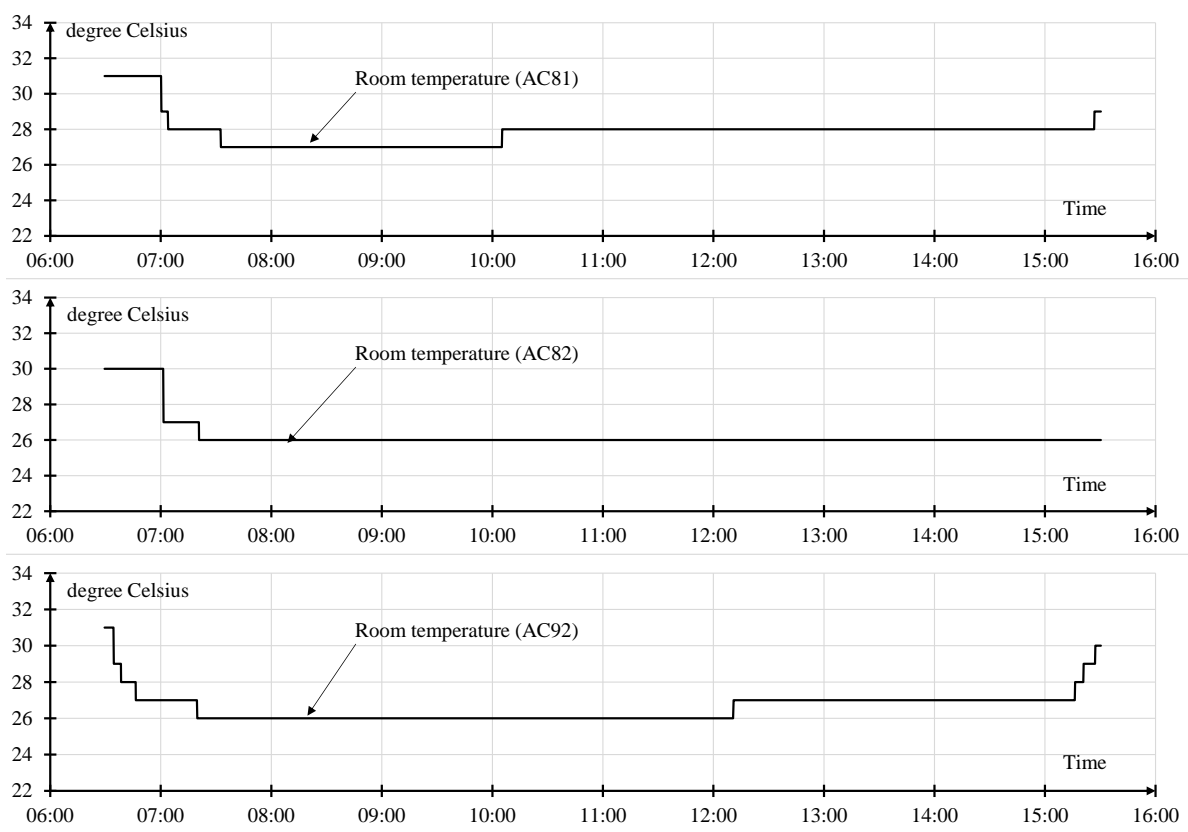

Figure 20. Room temperature on 12 October 2021.

\section{Discussion}

In this paper, we emphasize the cost-effective hardware and software solutions in the demand-side management procedure for the DR program, in which the temperature setpoint prediction model is just a supporting part of it. We implement the temperature setpoint prediction model by MATLAB 2021b and Deep Learning Toolbox. We construct the model without the network and constraint customization because we found that this model is accurate enough for energy reduction potential estimation for the building used in this paper. We believe that the more accurate prediction model is better for avoiding the penalty when the system cannot cope with the energy consumption as promised. However, the study on improving the prediction model is beyond the scope of this study. Therefore, the study on the prediction model will be conducted in future work. 


\section{Conclusions}

This paper presented the onsite implementation of DR with BEMS without voiding the warranty of the exiting equipment and without any additional measurements. With the limitation of the building characteristics, we proposed the DR control strategy during the $\mathrm{DR}$ event to reduce the power consumption of AC units with achieving the maximum power reduction at $43.79 \%$ of the maximum power consumption $(45.21 \mathrm{~kW})$ while ensuring the thermal comfort of occupants for more than $6 \mathrm{~h}$. This proposed solution will encourage the customer to join the DR program or another program of the smart grid operation. For the air conditioning system in the building, this paper also shows the practical result by using day-ahead temperature setpoint prediction to accept/decline DR requests from the utility operator or the load aggregator and schedule the AC temperature setpoint during the DR event. The collected building and weather data were used to train the setpoint prediction model. Then, we developed a classification neural network to determine the temperature setpoint of the ACs. During the DR event, the BEMS constantly monitors and controls the temperature setpoint of the ACs to maintain room temperature within the occupant comfort limit. The real-world, onsite experiment results show the practical applicability of the proposed method by reducing the power consumption of the ACs according to the DR request without disturbing the occupant's thermal comfort by keeping only $1{ }^{\circ} \mathrm{C}$ of difference from the typical room temperature. Future work will focus on integrating the proposed DR system with microgrids and distributed energy generation.

Author Contributions: Conceptualization, J.K. and P.C.; methodology, J.K. and P.C.; validation, J.K., P.C. and N.K.; formal analysis, J.K., P.C. and N.K.; investigation, J.K. and P.C.; resources, J.K., P.C. and N.K.; writing —original draft preparation, P.C.; writing — review and editing, J.K., P.C. and N.K.; visualization, J.K., P.C. and N.K.; supervision, J.K. All authors have read and agreed to the published version of the manuscript.

Funding: This research was funded by Metropolitan Electricity Authority (MEA) grant number RD0-0295-TXE-1.

Institutional Review Board Statement: Not applicable.

Informed Consent Statement: Not applicable.

Data Availability Statement: Not applicable.

Conflicts of Interest: The authors declare no conflict of interest.

\section{References}

1. Motegi, N.; Piette, M.; Watson, D.; Kiliccote, S.; Xu, P. Introduction to Commercial Building Control Strategies and Techniques for Demand Response; LBNL Report Number 59975; Lawrence Berkeley National Laboratory: Berkeley, CA, USA, 2007; pp. 47-54. [CrossRef]

2. Albadi, M.; El-Saadany, E. A summary of demand response in electricity markets. Electr. Power Syst. Res. 2008, 78, 1989-1996. [CrossRef]

3. Wang, S. Making buildings smarter, grid-friendly, and responsive to smart grids. Sci. Technol. Built Environ. 2016, 22, 629-632.

4. Shan, K.; Wang, S.; Yan, C.; Xiao, F. Building demand response and control methods for smart grids: A review. Sci. Technol. Built Environ. 2016, 22, 692-704.

5. Charoen, P.; Sioutis, M.; Javaid, S.; Charoenlarpnopparut, C.; Lim, Y.; Tan, Y. User-Centric Consumption Scheduling and Fair Billing Mechanism in Demand-Side Management. Energies 2019, 12, 156. [CrossRef]

6. Ahmad, A.; Hassan, M.; Abdullah, M.; Rahman, H.; Hussin, F.; Abdullah, H.; Saidur, R. A review on applications of ANN and SVM for building electrical energy consumption forecasting. Renew. Sustain. Energy Rev. 2014, 33, 102-109. [CrossRef]

7. Sherman, R.; Naganathan, H.; Parrish, K. Energy Savings Results from Small Commercial Building Retrofits in the US. Energies 2021, 14, 6207. [CrossRef]

8. EGAT. Annual Report 2020 Electricity Generating Authority of Thailand; Electricity Generating Authority of Thailand: Bangkok, Thailand, 2020; pp. 22-23.

9. Sehar, F.; Pipattanasomporn, M.; Rahman, S. An energy management model to study energy and peak power savings from PV and storage in demand responsive buildings. Appl. Energy 2016, 173, 406-417. [CrossRef]

10. Aduda, K.; Labeodan, T.; Zeiler, W.; Boxem, G.; Zhao, Y. Demand side flexibility: Potentials and building performance implications. Sustain. Cities Soc. 2016, 22, 146-163. [CrossRef] 
11. Aghniaey, S.; Lawrence, T.M. The impact of increased cooling setpoint temperature during demand response events on occupant thermal comfort in commercial buildings: A review. Energy Build. 2018, 173, 19-27. [CrossRef]

12. Watson, D.; Kiliccote, S.; Motegi, N.; Piette, M.A. Strategies for Demand Response in Commercial Buildings. In 2006 ACEEE Summer Study on Energy Efficiency in Buildings; European Council for an Energy Efficient Economy: Stockholm, Sweden, 2006; pp. 287-299.

13. Rabl, A.; Norford, L.K. Peak load reduction by preconditioning buildings at night. Int. J. Energy Res. 1991, 15, 781-798.

14. Turner, W.; Walker, I.; Roux, J. Peak load reductions: Electric load shifting with mechanical pre-cooling of residential buildings with low thermal mass. Energy 2015, 82, 1057-1067. [CrossRef]

15. Zhang, J.; Li, X.; Zhao, T.; Yu, H.; Chen, T.; Liu, C.; Yang, X. A Review of Static Pressure Reset Control in Variable Air Volume Air Condition System. Procedia Eng. 2015, 121, 1844-1850. [CrossRef]

16. Walaszczyk, J.; Cichon, A. Impact of the duct static pressure reset control strategy on the energy consumption by the HVAC system. E3S Web Conf. 2017, 17, 00095. [CrossRef]

17. Xue, X.; Wang, S.; Yan, C.; Cui, B. A fast chiller power demand response control strategy for buildings connected to smart grid. Appl. Energy 2015, 137, 77-87. [CrossRef]

18. Maneebang, K.; Methapatara, K.; Kudtongngam, J. A Demand Side Management Solution: Fully Automated Demand Response using OpenADR2.0b Coordinating with BEMS Pilot Project. In Proceedings of the 2020 International Conference on Smart Grids and Energy Systems (SGES), Perth, Australia, 23-26 November 2020; pp. 30-35. [CrossRef]

19. Alamin, Y.I.; Castilla, M.D.M.; Álvarez, J.D.; Ruano, A. An Economic Model-Based Predictive Control to Manage the Users' Thermal Comfort in a Building. Energies 2017, 10, 321. [CrossRef]

20. Kim, J.; Song, D.; Kim, S.; Park, S.; Choi, Y.; Lim, H. Energy-Saving Potential of Extending Temperature Set-Points in a VRF Air-Conditioned Building. Energies 2020, 13, 2160. [CrossRef]

21. Turley, C.; Jacoby, M.; Pavlak, G.; Henze, G. Development and Evaluation of Occupancy-Aware HVAC Control for Residential Building Energy Efficiency and Occupant Comfort. Energies 2020, 13, 5396. [CrossRef]

22. Macieira, P.; Gomes, L.; Vale, Z. Energy Management Model for HVAC Control Supported by Reinforcement Learning. Energies 2021, 14, 8210. [CrossRef]

23. Yang, K.; Su, C. An approach to building energy savings using the PMV index. Build. Environ. 1997, 32, 25-30. [CrossRef]

24. van Hoof, J. Forty years of Fanger's model of thermal comfort: Comfort for all? Indoor Air 2008, 18, 182-201. [CrossRef]

25. Toftum, J.; Andersen, R.; Jensen, K. Occupant performance and building energy consumption with different philosophies of determining acceptable thermal conditions. Build. Environ. 2009, 44, 2009-2016. [CrossRef]

26. Brager, G.S.; de Dear, R.J. Thermal adaptation in the built environment: A literature review. Energy Build. 1998, 27, 83-96. [CrossRef]

27. Hafeez, G.; Javaid, N.; Iqbal, S.; Khan, F.A. Optimal Residential Load Scheduling Under Utility and Rooftop Photovoltaic Units. Energies 2018, 11, 611. [CrossRef]

28. Wasim Khan, H.; Usman, M.; Hafeez, G.; Albogamy, F.R.; Khan, I.; Shafiq, Z.; Usman Ali Khan, M.; Alkhammash, H.I. Intelligent Optimization Framework for Efficient Demand-Side Management in Renewable Energy Integrated Smart Grid. IEEE Access 2021, 9, 124235-124252. [CrossRef]

29. Hafeez, G.; Alimgeer, K.S.; Wadud, Z.; Khan, I.; Usman, M.; Qazi, A.B.; Khan, F.A. An Innovative Optimization Strategy for Efficient Energy Management With Day-Ahead Demand Response Signal and Energy Consumption Forecasting in Smart Grid Using Artificial Neural Network. IEEE Access 2020, 8, 84415-84433. [CrossRef]

30. Hafeez, G.; Alimgeer, K.S.; Khan, I. Electric load forecasting based on deep learning and optimized by heuristic algorithm in smart grid. Appl. Energy 2020, 269, 114915. [CrossRef]

31. Hafeez, G.; Islam, N.; Ali, A.; Ahmad, S.; Usman, M.; Saleem Alimgeer, K. A Modular Framework for Optimal Load Scheduling under Price-Based Demand Response Scheme in Smart Grid. Processes 2019, 7, 499. [CrossRef]

32. Coughlin, K.; Piette, M.A.; Goldman, C.; Kiliccote, S. Statistical analysis of baseline load models for non-residential buildings. Energy Build. 2009, 41, 374-381. [CrossRef]

33. Wijaya, T.K.; Vasirani, M.; Aberer, K. When Bias Matters: An Economic Assessment of Demand Response Baselines for Residential Customers. IEEE Trans. Smart Grid 2014, 5, 1755-1763. [CrossRef]

34. Mohajeryami, S.; Doostan, M.; Schwarz, P. The impact of Customer Baseline Load (CBL) calculation methods on Peak Time Rebate program offered to residential customers. Electr. Power Syst. Res. 2016, 137, 59-65. [CrossRef]

35. Mohajeryami, S.; Cecchi, V. An investigation of the Randomized Controlled Trial (RCT) method as a Customer Baseline Load (CBL) calculation for residential customers. In Proceedings of the 2017 IEEE Power Energy Society General Meeting, Chicago, IL, USA, 16-20 July 2017; pp. 1-5. [CrossRef]

36. Mohajeryami, S.; Doostan, M.; Asadinejad, A.; Schwarz, P. Error Analysis of Customer Baseline Load (CBL) Calculation Methods for Residential Customers. IEEE Trans. Ind. Appl. 2017, 53, 5-14. [CrossRef]

37. Ministry of Energy, Thailand. National Smart Grid Master Plan (2015-2036); 2015. Available online: http://www.eppo.go.th/index. php/en/about-us/company-profile (accessed on 19 December 2021).

38. Ministry of Energy, Thailand. National Smart Grid Action Plan (2017-2021); Ministry of Energy: Bangkok, Thailand, 2016.

39. Mustafaraj, G.; Lowry, G.; Chen, J. Prediction of room temperature and relative humidity by autoregressive linear and nonlinear neural network models for an open office. Energy Build. 2011, 43, 1452-1460. [CrossRef] 
40. Ashtiani, A.; Mirzaei, P.A.; Haghighat, F. Indoor thermal condition in urban heat island: Comparison of the artificial neural network and regression methods prediction. Energy Build. 2014, 76, 597-604. [CrossRef]

41. Kong, W.; Dong, Z.Y.; Jia, Y.; Hill, D.J.; Xu, Y.; Zhang, Y. Short-Term Residential Load Forecasting Based on LSTM Recurrent Neural Network. IEEE Trans. Smart Grid 2019, 10, 841-851. [CrossRef]

42. Wang, Y.; Gan, D.; Sun, M.; Zhang, N.; Lu, Z.; Kang, C. Probabilistic individual load forecasting using pinball loss guided LSTM. Appl. Energy 2019, 235, 10-20. [CrossRef]

43. Srivastava, N.; Hinton, G.; Krizhevsky, A.; Sutskever, I.; Salakhutdinov, R. Dropout: A Simple Way to Prevent Neural Networks from Overfitting. J. Mach. Learn. Res. 2014, 15, 1929-1958.

44. Nair, V.; Hinton, G.E. Rectified Linear Units Improve Restricted Boltzmann Machines. In Proceedings of the 27th International Conference on International Conference on Machine Learning (ICML'10), Haifa, Israel, 21-24 June 2010; Omnipress: Madison, WI, USA, 2010; pp. 807-814.

45. Kingma, D.P.; Ba, J. Adam: A Method for Stochastic Optimization. arXiv 2017, arXiv:1412.6980. 